\title{
A COMPARATIVE STUDY OF ROUTINE MICROSCOPIC EXAMINATION OF URINE IN MICROBIOLOGY LABORATORIES AT PRIMARY AND SECONDARY LEVEL BEFORE AND AFTER IMPLEMENTATION OF STANDARD OPERATING PROCEDURE (SOP)
}

\author{
KHATUN K ${ }^{1}$, KAMAL AHMM ${ }^{2}$, RAHMAN KA ${ }^{3}$, HOSSAIN MZ ${ }^{4}$, RABIN N ${ }^{5}$, SHAMSUZZAMAN SM ${ }^{6}$, \\ HOSSAIN SZ ${ }^{7}$
}

\begin{abstract}
Context : Laboratory services have become an integral and inseparable component of modern medicine and public health. The use of standard operating procedure (SOP) in laboratory testing is one of the most crucial factor in achieving the quality. This cross sectional study was done to assess the quality of routine microscopic examination of urine of a microbiology laboratory at primary level and one microbiology laboratory at secondary level by evaluating the test results before SOP and re evaluating the test results after implementing SOP to see if there was any improvement in quality of those tests.
\end{abstract}

Material and Methods: A cross sectional, descriptive type of study was conducted in Narsingdi Sador Hospital as secondary level microbiology laboratory and Polash Upzilla Health Complex as primary level microbiology laboratory. The study was performed on clinically suspected patients of urinary tract infection (UTI) attending at the primary and secondary level laboratory for microscopic examination of urine. Clinically suspected cases of UTI who had taken any anti microbial treatment in the past 48 hours were excluded from the study. 60 urine samples were collected from each level before implementing SOP and 30 urine samples were collected from each level and tested after following SOP.

Result : In routine microscopic examination of urine at primary and secondary level, before $S O P$, regarding significant number of Pus cells discrepancy was found in $21.67 \%$ cases at primary level and $18.33 \%$ cases at secondary level. After implementing SOP, discrepancy in the result was reduced to $10 \%$ from $21.67 \%$ at primary level and $0 \%$ from $18.33 \%$ at secondary level. This difference in results was statistically significant $(p<0.05)$.

Conclusion: Implementing SOP and after practicing appropriate and standard techniques for collection and examination of urine at primary and secondary level, discrepancy in the results of routine microscopic examination of urine between investigator and Medical Officer (MOPathology) was reduced and overall quality of tests were improved.

Key words : Standard operating procedures (SOP), routine microscopic examination of urine, UTI, quality, discrepancy.

J Dhaka Med Coll. 2016; 25(2) : 87-93

\section{Introduction}

Quality means meeting the pre-determined requirements of the users for a particular substance or service. According to International Organization for Standards (ISO), quality is defined as totality of the characteristics of a product or service that make it suitable for the purpose for which it is intended ${ }^{1}$. In health laboratory services, the product is the report of analysis of the material received by the laboratory for processing i.e. laboratory testing and reporting. A standard

1. Dr. Khadeza Khatun, Assistant Professor, Department of Microbiology, Sir Salimullah Medical College, Dhaka.

2. Dr. A.H.M. Mostafa Kamal, Assistant Professor, Department of Anatomy. Dhaka Medical College, Dhaka.

3. Dr. Kazi Afzalur Rahman, Associate Professor, Department of Pharmacology, Dhaka Medical College, Dhaka.

4. Dr. Mohammad Zaid Hossain, Associate Professor, Department of Medicine, Dhaka Medical College, Dhaka.

5. Dr. Nadia Rabin, Lecturer, Department of Microbiology, Sir Salimullah Medical College, Dhaka.

6. Dr. S.M. Shamsuzzaman, Professor, Department of Microbiology, Dhaka Medical College, Dhaka.

7. Dr. Syed Zakir Hossain, Assistant Professor, Department of Medicine, Dhaka Medical College, Dhaka

Correspondence: Dr. Khadeza Khatun, Assistant Professor, Department of Microbiology, Sir Salimullah Medical College, Dhaka, Cell Phone: +8801742618959, E-mail: khadizakamal @yahoo.com 
operating procedure (SOP) is a set of written instructions that document a routine and repetitive activity and describe both technical and administrative as well as operational elements of an organization ${ }^{2}$. SOP must be written and implemented by a qualified laboratory officer and followed exactly by all members of the laboratory ${ }^{3}$. The use of standard operating procedures (SOP) in laboratory testing is one of the most crucial factor in achieving the quality ${ }^{4}$.

There are several components of a quality system. They should all be in place and operating before the end product of good quality laboratory report is likely to be achieved ${ }^{5}$.

In primary and secondary level laboratory, the scope for microbiological test is limited. Culture and sensitivity tests are not done at present but routine microscopic examination of urine, stool, malarial parasite in peripheral blood film (PBF), Gram staining, Ziehl-Neelsen staining of sputum and some serological tests (widal test, ASO titer etc.) are done almost in every laboratory at primary and secondary level ${ }^{3}$.

Urine samples are the most common and most numerous specimen analyzed for microbiological studies in the laboratory for diagnosis of various diseases like UTI. UTI is the most common of all bacterial infections and second only to RTI as cause of clinically significant morbidity due to infectious agents ${ }^{6}$.

Urinary tract infection is an inflammatory response of the urothelium to bacterial invasion that usually associated with bacteriuria and pyuria ${ }^{7}$. It associated with multiplication of organism in the urinary tract, and is defined by the presence of more than $10^{5}$ organism per $\mathrm{ml}$ in a midstream sample of urine ${ }^{8}$. Proper result can help to manage UTI in a specific manner and also help to avoid unnecessary, expensive and sometimes dangerous antibacterial treatment for nonexistence of infection.

Urinary tract infections are among the most common bacterial infections that lead patients to seek medical care. Approximately $10 \%$ of humans experience UTI at some time during their lives ${ }^{9}$. Such infections are much more common in women, cause considerable morbidity and account for $1.2 \%$ of all consultation in general practice ${ }^{8}$. It is estimated that $35 \%$ of healthy women suffer symptoms of urinary tract infection at some time in their life. The incidence of UTI increases markedly in the elderly and its prevalence is $1.4 \%$ among school children in Bangladesh ${ }^{10}$. Bacteriuria is found in $21 \%$ of women and $12 \%$ of men over 65 years of age ${ }^{11}$.

At present in Bangladesh, microbiology laboratories at different level usually do not follow any SOP for tests which may be the reasons for variation in test results from laboratories to laboratories for the same test. In this study, an attempt has been made to assess the quality of routine microscopic examination of urine in some microbiology laboratories at primary and secondary level with the aim to improve the quality of those tests after preparing and implementing SOP.

Materials and methods:

The present study was performed on clinically suspected patients of urinary tract infection (UTI) attending at the primary and secondary level laboratory for microscopic examination of urine. Clinically suspected cases of UTI who had taken any anti-microbial treatment in the past 48 hours were excluded from the study. 60 urine samples were collected from each level before implementing SOP and 30 urine samples were collected and tested from each level after following SOP. A cross sectional, descriptive type of study was conducted in Narsingdi Sador Hospital as secondary level microbiology laboratory and Polash Upzilla Health Complex as primary level microbiology laboratory.

Investigator: The student of thesis part M. Phil Microbiology course who was the principal investigator of the study and worked under direct supervision of guide and co-guide. The investigator tested all the samples by exactly following SOP of WHO guideline.

\section{Urine for routine microscopic examination and culture:}

A) Sample collection techniques for routine microscopic examination:

- Urine for routine microscopic examination was collected from the study population by 
the investigator both at primary and secondary level.

- Then collected urine specimen was divided into two parts. One was processed and examined in the laboratory by Medical Officer (MO) of Pathology department and the other was processed and examined by the investigator separately.

- Reports were kept in record and these were compared to evaluate the present status of test results at both level.

- Then a SOP for routine microscopic examination of urine was prepared by the investigator according to WHO guideline and the laboratory personnel were requested to follow that SOP.

- After implementing that SOP for 2 weeks, urine samples were collected again by the investigator and were examined in the same way by both investigator and MO (Pathology).

- Finally, results obtained by the MO (Pathology) were compared with that of the investigator to find out any improvement in quality of those tests after following SOP in those laboratories.

- Any difference in the results between investigator and MO (Pathology) was considered as discrepancy.

\section{B) Collection of urine specimen:}

After explaining proper procedure of urine collection, about $20 \mathrm{ml}$ of mid-stream clean catch urine was collected aseptically in a sterile container from the study population ${ }^{8}$. Each sample was properly labeled with date, time, ID no, name, registration no. and was transferred to the laboratory as early as possible.

C) Preservation and transport of urine sample: -All the urine samples collected from primary and secondary level laboratory for microscopy were placed in an ice box and were transferred to the tertiary laboratory as early as possible and were processed for microscopic examination.

\section{D) Microscopic Examination of urine ${ }^{12,5}$ :}

- Urine was mixed thoroughly by rotating the container. About $10 \mathrm{ml}$ of urine was poured off aseptically in a sterile labeled $15 \mathrm{ml}$ conical centrifuge tube and was centrifuged for 10 minutes at $1500 \mathrm{rpm}$.

- Supernatant was poured off carefully into another tube.

- Sediment was remixed by tapping the bottom of the tube and then one drop of well mixed sediment was placed on a clean dry glass slide and was covered with a cover slip.

- The urine was then examined under microscope with $10 \mathrm{X}$ objective to obtain an overall picture of the deposit and $40 \mathrm{X}$ objective was used to examine urine for pus cells, epithelial cells, RBC, casts, crystals etc. and was reported as follows:

- In urine sediment under $40 \mathrm{X}$ objective pus cells were reported as the number of pus cells/HPF. Pus cell 0-5/HPF was taken as test negative and Pus cell $>5 / \mathrm{HPF}$ was taken as test positive.

- Epithelial cells were reported as number of epithelial cells/HPF

- $\mathrm{RBC}$ were reported as number of $\mathrm{RBC} / \mathrm{HPF}$

- Crystal were reported as few, moderate or many/HPF

- Casts were reported as number of cast/LPF.

The results of the study were recorded systematically. Data analysis was done by using computer SPSS program and according to the objective of the study. Results were presented in the forms of tables. The tests of significance were calculated by using $\mathrm{x}^{2}$. $\mathrm{P}$ value $<0.05$ was taken as minimum level of significance, $\mathrm{P}$ value $<0.001$ was taken as highly significant.

\section{Ethical Clearance :}

This study was approved by the Ethical Review Committee of Dhaka Medical College, Dhaka.

\section{Results}

This cross sectional study was done to assess the quality of different tests at primary and secondary level laboratory. For this purpose, performance of MO (Pathology) of different laboratories was evaluated regarding sample collection, processing and procedure of testing for routine microscopic examination of urine before and after implementing SOP. Samples were collected and tested before and after implementing SOP. Difference in the results between the investigator and the MO (Pathology) was labeled as discrepancy. The 
results are presented in the following tables:

Table-I shows the results of microscopic examination of urine by the investigator and the MO (Pathology) of primary and secondary level laboratory before SOP. In case of primary level laboratory pus cells $0-5 / \mathrm{HPF}$ was found in $19(31.67 \%)$ cases and $>5 / \mathrm{HPF}$ was found in $41(68.33 \%)$ cases by the investigator. Pus cells $0-5 / \mathrm{HPF}$ was found in $32(53.33 \%)$ cases and pus cells $>5 / \mathrm{HPF}$ was found in $28(46.67 \%)$ cases by the MO (Pathology) of primary level laboratory. In case of secondary level laboratory (table-I) pus cells $0-5 / \mathrm{HPF}$ was found in $23(38.33 \%)$ cases and $>5 / \mathrm{HPF}$ was found in $37(61.67 \%)$ cases by the investigator. Pus cells $0-5 / \mathrm{HPF}$ was found in 34 (56.67\%) cases and pus cells $>5 / \mathrm{HPF}$ was found in 26(43.33\%) cases by the MO (Pathology) of secondary level laboratory. Significant number of pus cell $(>5 /$ HPF) was found more by the investigator than the MO (Pathology) and this difference is statistically significant..

At primary level, before SOP, microscopy of urine was found positive for pus cells in $41(68.33 \%)$ cases by the investigator and positive results for pus cells was found in 28(46.67\%) cases by the MO (Pathology) of primary level laboratory. At secondary level, microscopy was found positive for pus cells in $37(61.67 \%)$ cases by the investigator and positive results for pus cells was found in $26(43.33 \%)$ cases by the MO (Pathology). Significant number of pus cells $(>5 / \mathrm{HPF})$ was found more by the investigator than the MO (Pathology) and this difference is statistically significant (Table-II).

Table I

Microscopic findings of urine by the investigator and the MO (Pathology) of primary and secondary level laboratory before $S O P(n=60)$

\begin{tabular}{|c|c|c|c|c|c|c|}
\hline & \multicolumn{2}{|c|}{ Primary level } & \multicolumn{2}{|c|}{ Secondary level } \\
\hline \multicolumn{3}{|c|}{ Microscopic Finding } & Investigator(\%) & MO ((\%) & Investigator(\%) & $\mathrm{MO}(\%)$ \\
\hline \multirow{2}{*}{\multicolumn{2}{|c|}{$\begin{array}{l}\text { Pus cell } \\
\qquad 5 / \mathrm{HPF}\end{array}$}} & $0-5 / \mathrm{HPF}$ & 19(31.67) & $32(53.33)$ & $23(38.33)$ & $34(56.67)$ \\
\hline & & $41(68.33)$ & $28(46.67)$ & $37(61.67)$ & $26(43.33)$ & \\
\hline \multicolumn{2}{|c|}{ Epithelial cell } & 0-5/HPF & $29(43.33)$ & $37(61.67)$ & 43(71.67) & 44(73.33) \\
\hline & $>5 / \mathrm{HPF}$ & $31(51.67)$ & 23(38.33) & $17(28.33)$ & $16(26.67)$ & \\
\hline \multicolumn{2}{|c|}{ Red blood cell } & $0-2 / \mathrm{HPF}$ & 49(81.67) & $52(86.67)$ & $51(85.00)$ & $53(88.33)$ \\
\hline & $>2 / \mathrm{HPF}$ & $11(18.33)$ & $8(13.33)$ & $9(15.00)$ & $7(11.67)$ & \\
\hline \multirow[t]{2}{*}{ Cystal } & $\mathrm{Nil} / \mathrm{HPF}$ & $51(85.00)$ & $60(100.0)$ & $48(80.00)$ & $55(91.67)$ & \\
\hline & Present/HPF & $9(15.00)$ & $00(0.00)$ & $12(20.00)$ & $5(8.33)$ & \\
\hline \multirow[t]{2}{*}{ Cast } & Nil/HPF & $53(88.33)$ & $60(100.0)$ & $54(90.00)$ & $60(100.0)$ & \\
\hline & Present/HPF & $7(11.67)$ & $00(0.00)$ & $6(10.00)$ & $00(0.00)$ & \\
\hline
\end{tabular}

Figures in parentheses represent percentage. $\mathrm{MO}=$ Medical Officer (Pathology)

Table II

Results of microscopic examination of urine for pus cells at primary and secondary level laboratory before SOP

\begin{tabular}{lcccc}
\hline \multirow{2}{*}{ Microscopy Finding } & \multicolumn{2}{c}{ Primary level } & \multicolumn{2}{c}{ Secondary level } \\
Test positive & $41(68.33)$ & $28(46.67)$ & $37(61.67)$ & $26(43.33)$ \\
Test negative & $19(31.67)$ & $32(53.33)$ & $23(38.33)$ & $34(56.67)$ \\
\hline Total & $60(100.00)$ & $60(100.00)$ & $60(100.00)$ & $60(100.00)$ \\
\hline
\end{tabular}

Figures in parentheses represent percentage. $\mathrm{MO}=$ Medical Officer (Pathology)

Note: Pus cells 0-5/HPF was taken as test negative and Pus cells $>5 / \mathrm{HPF}$ was taken as test positive

For primary level

$\mathrm{X}^{2}$ value $\quad 4.910$

df 1

P value $\quad 0.027^{*}$
For secondary level

$\mathrm{X}^{2}$ value $\quad 3.342$

df $\quad 1$

P value $\quad 0.038^{*}$ 
After following SOP, in case of primary level laboratory pus cells $>5 / \mathrm{HPF}$ was found in $19(63.33 \%)$ cases by the investigator and pus cells $>5 / \mathrm{HPF}$ was found in $16(53.33 \%)$ cases by the MO (Pathology). In case of secondary level laboratory after SOP. pus cells $>5 / \mathrm{HPF}$ was found in $17(56.67 \%)$ cases by both the investigator and the MO (Pathology) (Table-III).

After following SOP, at primary level, microscopy was found positive for pus cells in 19(63.33\%) cases by the investigator and positive results for pus cells was found in $16(53.33 \%)$ cases by the MO (Pathology) of primary level laboratory. At secondary level, microscopy was found positive for pus cells in $17(56.33 \%)$ cases both by the investigator and the MO (Pathology) of secondary level laboratory (Table-IV).

Before SOP, discrepancy was found in 13(21.67\%) cases at primary level and at secondary level, discrepancy was found in $11(18.33 \%)$ cases with the investigator. After implementing SOP by the MO (Pathology) of primary level laboratory, discrepancy in the results of microscopic examination of urine between the investigator and the MO (Pathology) was reduced to $10 \%$ from $21.67 \%$. At secondary level laboratory, after implementing SOP by the laboratory MO (Pathology), discrepancy in the results of microscopic examination of urine was reduced to $0 \%$ from $18.33 \%$ and overall quality of the test reports were improved at both level (Table-V).

Table III

Microscopic findings of urine by the investigator and the MO (Pathology) of primary and secondary level laboratory after $S O P(n=30)$

\begin{tabular}{|c|c|c|c|c|c|c|}
\hline \multirow{2}{*}{\multicolumn{2}{|c|}{ Microscopic Finding }} & & \multicolumn{2}{|c|}{ Primary level $(\mathrm{n}=30)$} & \multicolumn{2}{|c|}{ Secondary level(n=30) } \\
\hline & & & Investigator(\%) & MO (\%) & Investigator(\%) & MO (\%) \\
\hline \multicolumn{2}{|c|}{ Pus cell } & $0-5 / \mathrm{HPF}$ & $11(36.67)$ & $14(46.67)$ & $13(43.33)$ & $13(43.33)$ \\
\hline & $>5 / \mathrm{HPF}$ & 19(63.33) & $16(53.33)$ & $17(56.67)$ & 17(56.67) & \\
\hline \multicolumn{2}{|c|}{ Epithelial cell } & $0-5 / \mathrm{HPF}$ & $16(53.33)$ & $18(60.00)$ & 19(63.33) & $20(66.67)$ \\
\hline & $>5 / \mathrm{HPF}$ & $14(46.67)$ & $12(40.00)$ & $11(36.67)$ & 10(33.33) & \\
\hline \multicolumn{2}{|c|}{ Red blood cell } & $0-2 / \mathrm{HPF}$ & $27(90.00)$ & $28(93.33)$ & $26(86.67)$ & $27(90.00)$ \\
\hline & $>2 / \mathrm{HPF}$ & $3(10.00)$ & $2(6.67)$ & $4(13.33)$ & $3(10.00)$ & \\
\hline \multirow[t]{2}{*}{ Cystal } & Nil/HPF & $26(86.67)$ & 29(96.67) & $27(90.00)$ & $28(93.33)$ & \\
\hline & Present/HPF & $4(13.33)$ & $1(3.33)$ & $3(10.00)$ & $2(6.67)$ & \\
\hline \multirow[t]{2}{*}{ Cast } & Nil/HPF & $29(96.67)$ & 30(100.0) & $30(100.0)$ & 30(100.0) & \\
\hline & Present/HPF & $1(3.33)$ & $00(0.00)$ & $00(0.00)$ & $00(0.00)$ & \\
\hline
\end{tabular}

Figures in parentheses represent percentage. $\mathrm{MO}=$ Medical Officer (Pathology)

Table IV

Results of microscopic examination of urine for pus cells at primary and secondary level laboratory after SOP.

\begin{tabular}{lcccc}
\hline & \multicolumn{2}{c}{ Primary level } & \multicolumn{2}{c}{ Secondary level } \\
Microscopy Finding & Investigator & MO & Investigator & MO \\
\hline Test positive & $19(63.33)$ & $16(53.33)$ & $17(56.37)$ & $17(56.33)$ \\
Test negative & $11(33.67)$ & $14(46.67)$ & $13(43.33)$ & $13(43.33)$ \\
\hline Total & $30(100.00)$ & $30(100.00)$ & $30(100.00)$ & $30(100.00)$ \\
\hline
\end{tabular}

Figures in parentheses represent percentage. $\mathrm{MO}=$ Medical Officer (Pathology)

Note: Pus cells $0-5 / \mathrm{HPF}$ was taken as test negative and Pus cells $>5 / \mathrm{HPF}$ was taken as test positive

For primary level

$\begin{array}{ll}\mathrm{X}^{2} \text { value } & 0.274 \\ \mathrm{df} & 1 \\ \mathrm{P} \text { value } & 0.601^{\mathrm{ns}}\end{array}$
For Secondary level

$\mathrm{X}^{2}$ value $\quad 0.000$

df 1

P value $\quad 1.000^{\text {ns }}$ 
Table-V

Discrepancy in the results of microscopic examination of urine for pus cells before and after implementing SOP by the Medical Officer (Pathology) of primary and secondary level laboratory.

\begin{tabular}{lcccc}
\hline Microscopy outcome & \multicolumn{2}{c}{ Primary level } & \multicolumn{2}{c}{ Secondary level } \\
& Before SOP & After SOP & Before SOP & After SOP \\
\hline \multirow{3}{*}{ Discrepancy } & $(\mathrm{n}=60)$ & $(\mathrm{n}=30)$ & $(\mathrm{n}=60)$ & $(\mathrm{n}=30)$ \\
No discrepancy & $13(21.67)$ & $3(10.00)$ & $11(18.33)$ & $0(0.00)$ \\
\hline
\end{tabular}

Figures in parentheses represent percentage.

For primary level

$\begin{array}{ll}\mathrm{X}^{2} \text { value } & 1.150 \\ \mathrm{df} & 1\end{array}$

$P$ value $\quad 0.028^{*}$

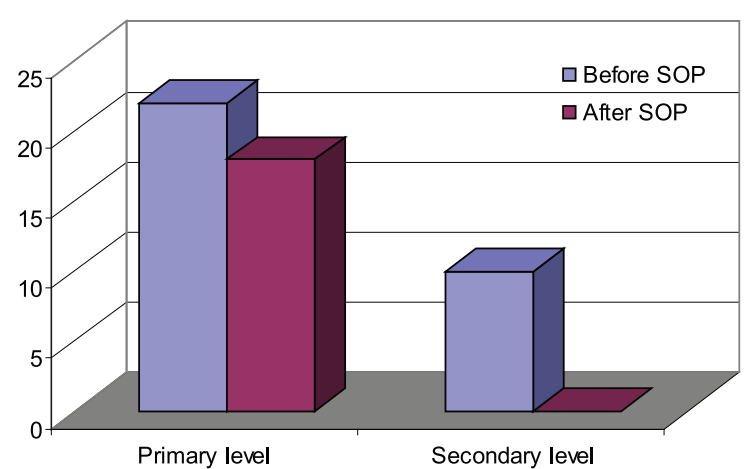

Fig.-1: Discrepancy in the results of microscopic examination of urine for pus cells before and after implementing SOP by the Medical Officer (Pathology) of primary and secondary level laboratory.

\section{Discussion:}

The role of diagnostic medical laboratories in saving life is well established today. These laboratories with their timely and correct reporting aid the physicians in their treatment. In the present study, it was made to see the extent of difference in results between investigator and $\mathrm{MO}$ (Pathology) of primary and secondary level laboratory before and after implementing SOP. If there was any difference in results between the investigator and the MO (Pathology) then it was considered as discrepancy.

Microscopic examination of urine is the most common laboratory procedure used for the detection of urinary tract diseases ${ }^{13}$. At
For Secondary level

$\mathrm{X}^{2}$ value $\quad 4.673$

df 1

$\mathrm{P}$ value $\quad 0.031^{*}$

primary level laboratory, before SOP out of 60 urine sample from suspected cases of UTI for routine microscopic examination, pus cells $>5 / \mathrm{HPF}$ was found in $41(68.33 \%)$ cases by the investigator and in $28(46.67 \%)$ cases by the $\mathrm{MO}$ (Pathology) (Table-I). Moderate number of oxalate crystal / HPF (5-10 crystal/ HPF) was reported in $9(15 \%)$ cases by the investigator but crystal was reported as nil/HPF when the same samples were examined by the MO (Pathology). At secondary level laboratory, before SOP out of 60 urine samples, pus cells $>5 / \mathrm{HPF}$ was found in $37(61.67 \%)$ cases by the investigator and in 26(43.33\%) cases by the MO (Pathology) (Table -I).

Discrepancy in the reports before SOP regarding significant number of pus cell between the investigator and the MO (Pathology) was found in 13(21.67\%) cases at primary level and $11(18.33 \%)$ cases at secondary level. After implementing and practicing a SOP for routine microscopic examination of urine by the MO (Pathology) of primary and secondary level laboratory, discrepancy in the result was reduced to $10 \%$ from $21.67 \%$ at primary level and $0 \%$ from $18.33 \%$ at secondary level (Table-V).

Before SOP, significant number of pus cell ( $>5$ / $\mathrm{HPF}$ ) was found more by the investigator than the MO (Pathology) at both level and this difference in results between investigator and MO (Pathology) was statistically significant ( $\mathrm{p}<$ 0.5) (Table-II). For routine microscopic 
examination, urine should be properly preserved if it is not immediately processed (within 2 hours) in the laboratory. If unpreserved urine is left at room temperature white cells, red cells, casts present in the urine will begin to lyse ${ }^{1}$. In the present study, it was found that, the laboratory MO (Pathology)s usually collected all the samples from 9 am to $12.30 \mathrm{pm}$ and then made preparation for processing the samples without proper preservation of the collected specimens in case of delay $>2$ hours. Again during the processing of samples, standard method of centrifugation was not followed properly by them (for 10 minutes at $1500 \mathrm{rpm}$ ). These might be the reasons of difference in results of microscopic examination of urine between the investigator and the MO (Pathology) before SOP.

After implementing SOP for routine microscopic examination, discrepancy in the results between investigator and $\mathrm{MO}$ (Pathology) was reduced at both level and this difference in results was not statistically significant ( $p>0.5)$ (Table-III,IV). It was found that, if the MO (Pathology)s could be given adequate training under the direct supervision of an expert and if they follow a standard operating procedure as a practical guide line for each test, then the skill of the MO (Pathology) as well as overall quality of the tests would also improve.

\section{Conclusion:}

It might be concluded that, the use of standard operating procedure (SOP) as practical guideline in laboratory services, aimed at improving the reliability and efficiency in laboratory testing is the backbone of quality health care delivery at primary and secondary level. Every laboratory must follow standard operating procedure (SOP) manuals in laboratory testing. Proper training of the MO (Pathology)s of primary and secondary level laboratories should be done periodically and they should be instructed to follow the SOP strictly under the super vision of a qualified microbiologist. Collection of urine for microscopic examination should be done in proper and aseptic technique following SOP. If the MO (Pathology)s could be given adequate training periodically and being continuously monitored by qualified supervising authority to strictly follow the SOP then the quality of the test would also improve.

\section{Acknowledgement:}

We would like to pay our gratitude to the authority of Bangladesh Medical Research Council (BMRC) for providing us with the partial grant for the study.

\section{References:}

1. WHO, 2003. Treatment of Tuberculosis: Guidelines for National programmers, $3^{\text {rd }}$ edition. Geneva, Switzerland: World Health Organization; 2003: 11-40.

2. Arora DR. Quality assurance in Microbiology. Indian J Med Microbiol 2004; 22(2): 81- 6.

3. Hoque ABMT, Musa SAJM, Hasal A. Guideline and SOP for Government and Private Laboratories, $1^{\text {st }}$ edition. 2008: 70-5.

4. WHO, 2000. Quality Asssurance. In : Kumari S, Inchhpujani RL, editors. Guideline on standard operating procedures for Microbiology, $2^{\text {nd }}$ edition. New Delhi, India: World Health Organization; 2000: $150-79$.

5. Cheesbrough M. Total quality management of district laboratory services. In: District Laboratory Practice in Tropical Countries. Part 1. UK: Cambridge University Press; 2000: 44-9.

6. Graham JC, Galloway A, Turner AN. The laboratory diagnosis of urinary tract infection. J Clin Pathol 1997;54:911-19.

7. Schaeffer AJ. Infections of the urinary tract. In : Walsh PC, Retik AR Vaughan ED, Wein AJ, editors. Campbell's Uroloy, $8^{\text {th }}$ edition. Philadelphia: WB saunders Company; 1998: 63941.

8. Goddard J, Tutner AN, Cumming AD, Stewart LH. Kidney and urinary tract disease. In: Boon NA, Colledge NR, Walker BR, Hunter JAA, editors. Davidson's principles and practice of Medicine, $20^{\text {th }}$ edition. Edinburg: Churchill-Livingstone; 2006: 508- 11 .

9. Forbes BA, Sahim DA, Weissfeld AS. General Issues in Clinical Microbiology. In: Bailey \& Scott's diagnostic microbiology. 11th edition. USA: Mosby Inc; 2002: 155-60.

10. Rahman M. Prevalence of asymptomatic bacteriuria due to E.coli in children and pregnant women. [ M.Sc thesis] Draka:University of Dhaka; 1994: 62-4.

11. Lee LB, Neild HG. Urinary tract infection. Medicine. 2007; 35:8: 423-28.

12. Collee JG, Duguid JP, Fraser AG, Marmion BP. Laboratory strategies in the diagnosis of infections syndromes. In: Collee JG, Barrie MP, Farser AG, Simmons A, editors. Mackie \& McCartney Practical Medical Microbiology, $14^{\text {th }}$ edition. New York: Churchill Livingstone; 1996: 53-63.

13. Fuller CE, Threatte GA, Henry JB. Basic examination of urine. In Henry JB, Threatte GA editors. Clinical Diagnosis and Management by Laboratory methods, $20^{\text {th }}$ edition. Philadelphia :WB Saunders company; 2001: 398-402. 